\title{
Teaching Quality about Application of Multimedia in Higher Education
}

\author{
Ling $\mathrm{Xu}$ \\ College of Economics \& Management, \\ QingDao University of Science and Technology \\ QingDao,China \\ e-mail: xlxqh@163.com
}

\begin{abstract}
Application of multimedia in high school is very popular. How the teaching quality in multimedia class needs further development. This paper foucs on the teaching quality in multimedia education in universities in China.First factors that influence teaching qualities are introduced.And then teaching quality in Chinese universities about multimedia is investigated. Then method of Analytic Hierarchy Process (AHP) is used to ensure which factor is most important for teaching quality.As the results show quality of PPT and ability to control class are the most important factors.
\end{abstract} AHP

Keywords-multimedia;teaching quality; higher education;

\section{INTRODUCTION}

Application of multimedia in high school is very popular $^{[1]}$. Rapid development of science and technology makes it possible to use all kind of multimeadia tools in teaching.Multimedia contrubutes much in teaching quality ${ }^{[2]}$.Then how the teaching quality in multimedia class needs further development.

This paper foucs on the teaching quality in multimedia education in universities in China.In the first part factors that influence teaching quality are introduced.And then teaching quality in Chinese universities about multimedia is investigated. Then method of The Analytic Hierarchy Process (AHP) ${ }^{[3]}$ is used to ensure which factor is most important for teaching quality.And the next section showes the results and the final section draws a conclusion.

\section{FACTORS INFLUENCING MUILTIMEDIA TEACHING QUALITY}

A lot of factors can influence multimedia teaching quality. In order to find the factors that influence multimedia teaching quality,the author does investigations in universities and colleges in China.Teachers, management man in universities,academicians are involved in investigation.At last 142 questionnaires are selected for futher research. After sthdy on the questionnaires, four main factors are showed influence multimedia teaching quality. The four factors are teacher,instruments for multimedia, management and students.
Factors about teacher are quality of $\mathrm{PPT}^{[4]}$, ability to control class, resources offered after class, ability of cooperation and ability of using multimedia instruments.

Factors about instruments for multimedia include offering of instruments and technich support.

Factors about management include examination on PPT ,management on instruments and training management.

Factors about students include favour of multimedia, adaptability of multimedia and class atmosphere when using multimedia.

\section{METHOD}

After factors influencing multimedia teaching quality are found, the next proceeding is to find which is the most important factors. So mainly factors and secondary factors can be ensured. Then how to know? Method of Analytic Hierarchy Process(AHP) is helpful for this goal.

Analytic Hierarchy Process(AHP $)^{[5]}$ is used in this paper for further analysis.It is a popular and widely used method for multi-criteria decision making. In this paper it helps to determine the relative weights of factores that influencing multimedia teaching quality. The factors are decomposed into three hierarchies. Factors in the same hierarchy carry weight to their top hierarchy and at the same time they carry weigh to hierarchy below them. Hierarchy tree is listed in figure 1.

Acording to hierarchy tree,pairwise comparisons are made to build comparison matrix. And then criteria weights are got by using Eigenvector after calculating a Consistency Ratio (CR) and Consistency index $(\mathrm{CI}<0.1, \mathrm{CR}<0.1)$. So we can know how much is each factor affects multimedia teaching quality .

In order to measure well, teachers and students in universities are invited to score. Pairwise comparisons are made with the grades ranging from 1-7." 1 "showes the two factors contribute equally to objective. " 3 "showes that one factor is somewhat more important than the other. " 5 "showes that one factor is much more important than the other. "7"shows that one factor is absolutely more important than the other. If attribute A is absolutely more important than attribute $\mathrm{B}$ and is rated at 7 , then $\mathrm{B}$ must be absolutely less important than A and is graded as 1/7. 


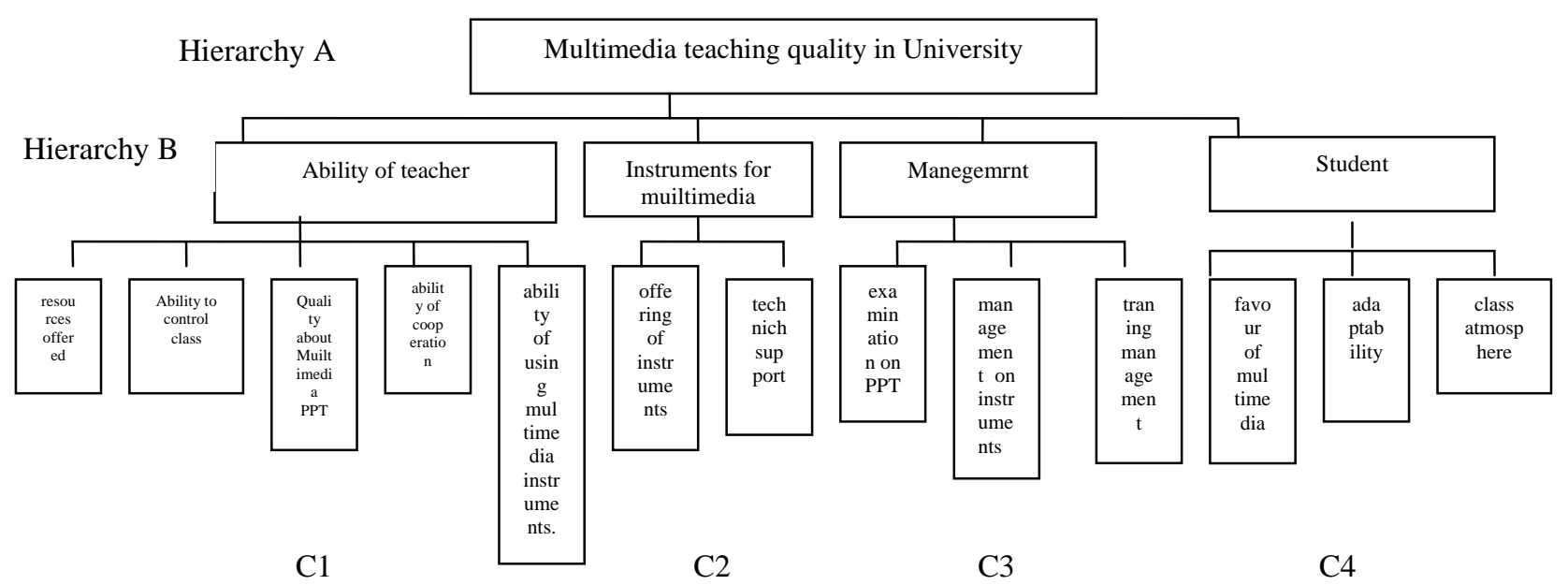

Figure 1. Structure for hierarchy

\section{RESULT}

According to structure for hierarchy, pairwise comparisons are made to build comparison matrix.Three hierarchies are seperated named A, B and C hierarchy. Comparison matrices in $\mathrm{C}$ hierarchy are named C1,C2,C3 and $\mathrm{C} 4$ from left to right. So comparison matrices in the three hierarchies are showed below.

$$
\begin{gathered}
B=\left[\begin{array}{cccc}
1 & 7 & 5 & 2 \\
1 / 7 & 1 & 2 & 1 / 5 \\
1 / 5 & 1 / 2 & 1 & 1 / 5 \\
1 / 2 & 5 & 5 & 1
\end{array}\right] \\
C_{1}=\left[\begin{array}{ccccc}
1 & 1 / 5 & 1 / 7 & 1 / 4 & 2 \\
5 & 1 & 1 / 4 & 1 / 2 & 5 \\
7 & 4 & 1 & 4 & 6 \\
4 & 2 & 1 / 4 & 1 & 5 \\
1 / 2 & 1 / 5 & 1 / 6 & 1 / 5 & 1
\end{array}\right] \\
C_{2}=\left[\begin{array}{cc}
1 & 5 \\
1 / 5 & 1
\end{array}\right] \\
C_{3}=\left[\begin{array}{ccc}
1 & 1 / 7 & 1 / 2 \\
7 & 1 & 9 \\
2 & 1 / 9 & 1
\end{array}\right] \\
C_{4}=\left[\begin{array}{ccc}
1 & 4 & 3 \\
1 / 4 & 1 & 2 \\
1 / 3 & 1 / 2 & 1
\end{array}\right]
\end{gathered}
$$

Then weight vectors(w), Eigenvector and Consistency index(CI) are caiculated according to comparison matrix. The results are showed in table 1 and table 2.

TABLE I. RESULTS IN C HIERARCHY

\begin{tabular}{|l|l|l|l|c|}
\hline Factors & \multicolumn{1}{|c|}{$\mathbf{1}$} & \multicolumn{1}{|c|}{$\mathbf{2}$} & $\mathbf{3}$ & $\mathbf{4}$ \\
\hline $\mathrm{w}$ & 0.0621 & 0.8333 & 0.0872 & 0.6196 \\
& 0.1812 & 0.1667 & 0.7849 & 0.2243 \\
& 0.4962 & & 0.1279 & 0.1560 \\
& 0.2136 & & & \\
\hline$\lambda$ & 0.0468 & & & \\
\hline $\mathrm{CI}$ & 5.3295 & 2 & 3.10299 & 3.10927 \\
\hline $\mathrm{CR}$ & 0.08245 & 0 & 0.051494 & 0.05464 \\
\hline
\end{tabular}

TABLE II. RESULTS IN B HIERARCHY

\begin{tabular}{|l|l|}
\hline \multicolumn{1}{|c|}{ Factors } & \multicolumn{1}{c|}{$\mathbf{1}$} \\
\hline $\mathrm{w}$ & 0.5085 \\
& 0.0911 \\
& 0.0703 \\
\hline$\lambda$ & 0.3301 \\
\hline $\mathrm{CI}$ & 4.13944 \\
\hline $\mathrm{CR}$ & 0.046482 \\
\hline
\end{tabular}

Acording to the above results, integrated weight vectors

$w_{c i}$ are showed below.

$w_{c i}=\left(\begin{array}{l}0.03156,0.09216,0.25234 \not 0.10863,0.02379, \not 0.075889 \\ 0.01517 \varnothing .00613,0.05519,0.00899,0.20453,0.07405,0.05150 \%\end{array}\right)$ 


\section{CONCLUSION}

So as the results show quality of PPT, ability to control class, favour of multimedia,ability of cooperation, ability to control class are more important factors that influence multimedia teaching qulity.Of all the factors, quality of PPT and ability to control class are the most important factors. The two factors are both about teachers. So teachers should do the PPT well and enhance the ability to control the class well. As for the students, to what extent they favor multimedia teaching also have effects on teaching quality.

\section{REFERENCES}

[1] San Peihong,Tang Lei,Li Xinwang, “On Bulding a Fuzzy Comprehensive Evaluation Model for Multimedia Teaching Quality and a Case Analysis”, Journel of Jiangxi Institute of Education , Vol8,Mar.2010, pp.41-44

[2] LIU Yan, "Establishment of Assessment System on Multimedia Teaching Quality of Mathematics Subjects and a Case Analisis”,Journel of Henan Mechenical and Electrical Engineering College.Vol 19,Mar.2011.pp.115-117

[3] REN Chen-Ling, "on Quality Factors of Multimedia Teaching and Countermeasures in Colleges",Journel of Jiangxi Institute of Education. Vol 32,Feb.2011, pp.94-96

[4] CHEN Jun, "Establishment of Assessment System on Multimedia Teaching Quality”,Theory and Practice of Education, Vol21,2008, pp.25-27

[5] Li Kun, "Assessment on the Quality of Multimedia Teaching Based on AHP Method”,Journal of Jixi University, May.2011,pp.35-36 